\title{
RESEARCH ON DESIGN METHOD FOR THE BLUE-GREEN ECOLOGICAL NETWORK SYSTEM TO DEAL WITH URBAN FLOODING: A CASE STUDY OF CHARLESTON PENINSULA
}

\author{
ZHITONG LIANG ${ }^{1}$, ROBERT REID HEWITT ${ }^{2}$ \& YAN DU ${ }^{1}$ \\ ${ }^{1}$ Key Laboratory of Urban Agriculture in Central China, Ministry of Agriculture and \\ Rural Affairs, Huazhong Agricultural University, China. \\ ${ }^{2}$ Clemson University, United States of America.
}

\begin{abstract}
The landscape strategy to deal with climate change has become an important issue in the process of sustainable urban development in the world. Particular focus is given to the Charleston Peninsula in South Carolina, USA, which faces floods due to inefficiency in stormwater collection systems, increased frequency of intense rain events, excessive impervious surfaces, tide cycles, etc. In addition, hurricane events and sea-level rise are considered sources of flood risk in the coastal areas of the peninsula. This research draws on existing urban stormwater management theory to argue that the blue and green water ecological network system in the built-up area represents an innovative approach to alleviate flooding and promote a healthy landscape during urban renewal. According to the analysis of hydrological characteristics, the peninsula is divided into 17 basins, and then each basin is studied separately. Within Basin 8 , the potential block is divided into four types of functional stormwater management units (fast flow zone, absorption containment zone, additional digestion zone, and upstream interception zone) and connected by a reintegrated drainage system. Finally, the corresponding micro-landscape strategy is proposed according to the block property. Functional units simultaneously undertake the functions of rainwater management and landscape activities. In the end, the new active-recreation space and passive-recreation space in the network are connected with the original urban green space and provide the city with a series of unique ecosystem services to support urban drainage systems and human health. It is hoped this research will provide an attempt for future urban stormwater management from the perspective of landscape planning and design.

Keywords: blue-green ecological network system, hydrological process, landscape architecture, public space system, stormwater management unit.
\end{abstract}

\section{INTRODUCTION}

Although there are already mature examples of rainwater management, such as Best Management Practices (BMP), Sustainable Urban Drainage System (SUDS), and Water Sensitive Urban Design (WSUD), the research on the sustainable management of rainwater systems for climate change is still rising. Its essence is to control surface runoff, reduce water pollution, and restore the integrity of ecosystems [1]. Among them, stormwater control measures (SCMs) capture and retain rainwater through on-site infiltration, remove rainwater pollutants, and minimize rainwater runoff [2]. When SCMs are integrated into the basin in an appropriate manner, they do not affect the water quality of natural water bodies [3]. In addition, research on green infrastructure (GI) has shown that it has a positive effect on reducing stormwater runoff. Through different combinations of low-impact development strategies, rainwater runoff can be effectively reduced for individual land use and even for the entire basin [4].

Similar to many cities, Charleston's natural hydrological process was disrupted by urban development. However, its geographical location and special historical and social factors make it face more frequent and complicated flood disasters. Based on the characteristics of hydrological processes, this study attempts to build a stormwater management plan based on the blue and green ecological network system of the peninsula. 


\section{BACKGROUND}

The Charleston Peninsula is located at the entrance to the Atlantic Ocean in southern South Carolina, USA, and is surrounded by the Ashley River and the Cooper River (Fig. 1). Charleston has ample rainfall throughout the year, with approximately half of the annual rainfall concentrated between June and September. The rainy season has an average of 25 days of rainfall per month. In addition, under the influence of global climate change, extreme weather, such as hurricanes, is appearing at a higher frequency. Between 2015-2017, strong hurricanes entered the Charleston Peninsula three times, bringing heavy rainfall and storm surges up to 3 meters [5]. On sunny days, the tides only cause floods in a small area near the coast. However, as the sea level rises, the land area that is submerged by seawater during high tide expands further [6]. All of these factors have brought surface runoff to Charleston, which is the cause of floods. According to data from the National Oceanic and Atmospheric Administration (NOAA) of the United States, Charleston's nuisance floods have increased by $400 \%$ since the 1960 s.

Surface runoff is accompanied by evaporation and infiltration that then flows into the drainage system or flows along natural terrain. The peninsula has a relatively flat terrain and complex microtopography that causes surface floods to remain and impedes effective surface water collection systems. Urban expansion has brought a large amount of impervious ground and laterally increased the peak surface runoff. At the same time and due to the long history of construction, the pipe sizes are not appropriate, and the drainage efficiency is greatly affected by the tide situation. This is far from meeting the needs of contemporary drainage.

As one or more of the factors listed in the current text for city surface runoff are superimposed, Charleston has to face frequent floods due to poor surface water supplies and inefficient drainage systems. In recent years, Charleston has placed great emphasis on flood management, focusing on the construction of engineering systems and GIs for low-impact development. However, the low-impact development measures focus on encouraging selfindividual behavior: encouraging residents to increase the green area, achieving preliminary rainwater harvesting, and utilizing green roofs and rain gardens in private housing. There is a lack of systematic and effective planning at the city level. Based on this, the concept of the blue-green ecological network was proposed to explore the construction method of ecological rainwater-guiding landscape systems applicable to the Charleston Peninsula. Based on the characteristic analysis of the hydrological cycle process, flood management is carried out by means of landscape intervention to alleviate the urban flood pressure. At the same time, it complements the urban open-space system.

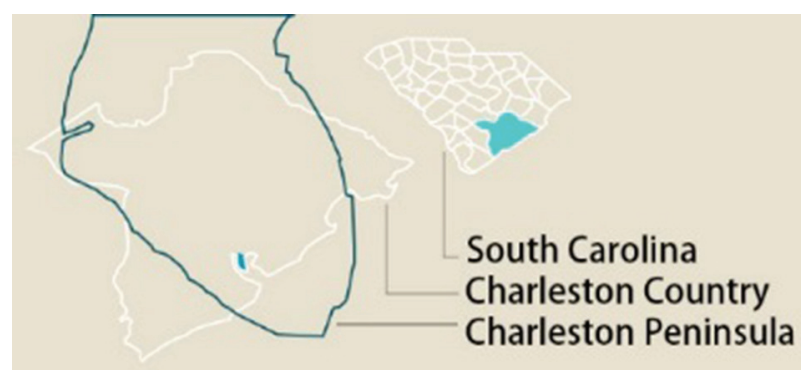

Figure 1: Location of the Charleston Peninsula. 


\section{CHARLESTON PENINSULA CASE STUDY: SOURCES AND METHODS}

The concept of the blue-green network system is not new and has been incorporated into general urban planning based on rain and flood management [7]. At the national level and even on a transnational scale, the ecological value of blue-green networks is very prominent, making it a kind of background ecological network [8-9]. This is a blue-green network concept from the perspective of landscape ecology. However, the blue-green network system in this study refers to an urban space network system formed by a combination of blue and green infrastructures. Urban stormwater management should emphasize small-scale restoration or conservation of natural hydrological processes [10]. When the concept of blue-green networks is applied to the urban watershed management target, how should this network be built? What is the basis of it? The construction of the network system in this study consists of three main steps: analysis of peninsula hydrological characteristics and basin division, reorganization of surface runoff confluence and establishment of stormwater management units for specific basin, and realization of landscape ecological functions (the second and third steps are summarized in section 4.2).

\subsection{Peninsula hydrologic analysis and basin division}

Data from government agencies' websites and documents were collected first, and the risk maps of different types of flood disasters (such as storm, tide, and storm surge) were sorted. Among them, floods caused by heavy rainfall are the most widespread and frequent disaster type. The construction of blue-green networks requires interdisciplinary research methods [11]. In the next step, GIS hydrological analysis was performed using DEM data with a precision of $3.0 \mathrm{M}$ downloaded from the NOAA website to establish an overall understanding of the basic hydrological characteristics of the peninsula. Digital elevation models (DEM) are widely used in various environmental studies and are commonly used to obtain information on flow directions, flow accumulation, drainage networks, and watershed partitioning [12]. Hydrologic analysis tools in ARCGIS software are used to carry out filling analysis, define flow direction, capture river network outlets, extract flow network and flow network classification, etc.; a surface runoff classification diagram, runoff flow direction diagram, and basin zoning map automatically divided by the program can be obtained for the whole peninsula. The hydrological analysis results can solve two problems: (1) the flow direction and grade of surface runoff during rainfall, and (2) the division of the basin.

\subsection{Construction of blue-green network for a specific basin}

The result of basin division is the basis of further hydrologic research [13]-[14]. Artificial integration is also required for basins obtained in the previous step, which are automatically divided according to the outlet of the river network. This defines an area where tributaries eventually converge at the same outlet as a large basin. According to this principle, the small watershed is integrated, and finally the basin zoning result required for planning and design is obtained. Therefore, the confluence process of each basin is independent, which is the scientific support for the logic of subdivision management of peninsula flooding. One of the basins will be selected to demonstrate the construction of a blue-green network system in this section. 


\subsubsection{Basic information}

Data on land cover types and flood distribution during the once-in-a-decade rainstorm events in the basin (hereafter referred to as the flood area) were mapped on the satellite map. Flood area and runoff maps generated by high-precision DEM were mutually verified to evaluate their reliability.

3.2.2 Analysis of comprehensive confluence process and flood detention reasons in the basin The influence and function of underground drainage networks in urban basins cannot be ignored. At this stage, the analysis results of the SWMM model were used as an important reference for planning. SWMM developed in 1971 by the United States Environmental Protection Agency (USEPA, 2000), and is widely used in simulation, analysis, and design [15]. The National Oceanic and Atmospheric Administration (NOAA) has published an analysis of how drainage networks operate under various conditions using the SWMM model for similar regions of designated basins. In this paper, the analysis results are statistically collated and visualized on satellite images. It makes sense to have a clear understanding of the breakdown thresholds for the drainage system. This factor can be geographically calibrated and superimposed on the distribution of flood areas. The cause of the water accumulation can be preliminarily speculated based on these data; it may be due to the inability of runoff to reach the inlet or the fact that the runoff is far beyond the drain's load.

\subsubsection{Rainwater management unit and surface confluence route}

Flood areas, areas through which primary runoff flows (including adjacent areas), are divided into plots bounded by urban roads. After recording the statistics of land type, ownership, area, and other factors, the stormwater management potential of various plots was assessed subjectively. Stormwater management potential, location relationship between plots and runoff, and causes of flooding become the basis for defining rainwater management units (Fig. 2), which will be described in detail below. Urban landscape-based stormwater infiltration systems are typically modular, rely on a minimum of hard engineering, operate by gravity, and therefore are defined by local and microtopography [16]. The original runoff route was adjusted according to the distribution of various stormwater management units. The guidance of surface runoff mainly depends on microtopography and low-level engineering methods. The corresponding rainwater control function is given to the different land parcels, making it a stormwater management unit, and the units are connected to the restored water system to form a natural drainage network with both flood storage and flood discharge capacity.

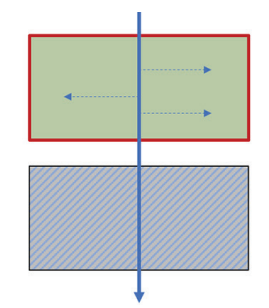

Upstream Interception Zone

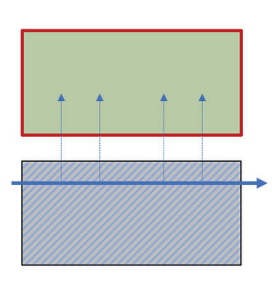

Additional Digestion Zone

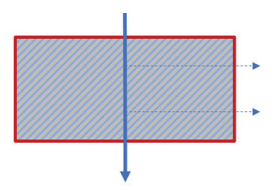

Fast Flow Zone

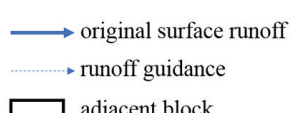

$\square$ adjacent block stormwater management units

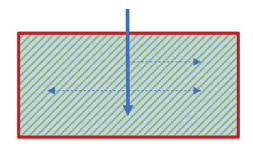

Absorption Containment Zone

high potential low potential Flooded area

Figure 2: Four types of stormwater management units. 


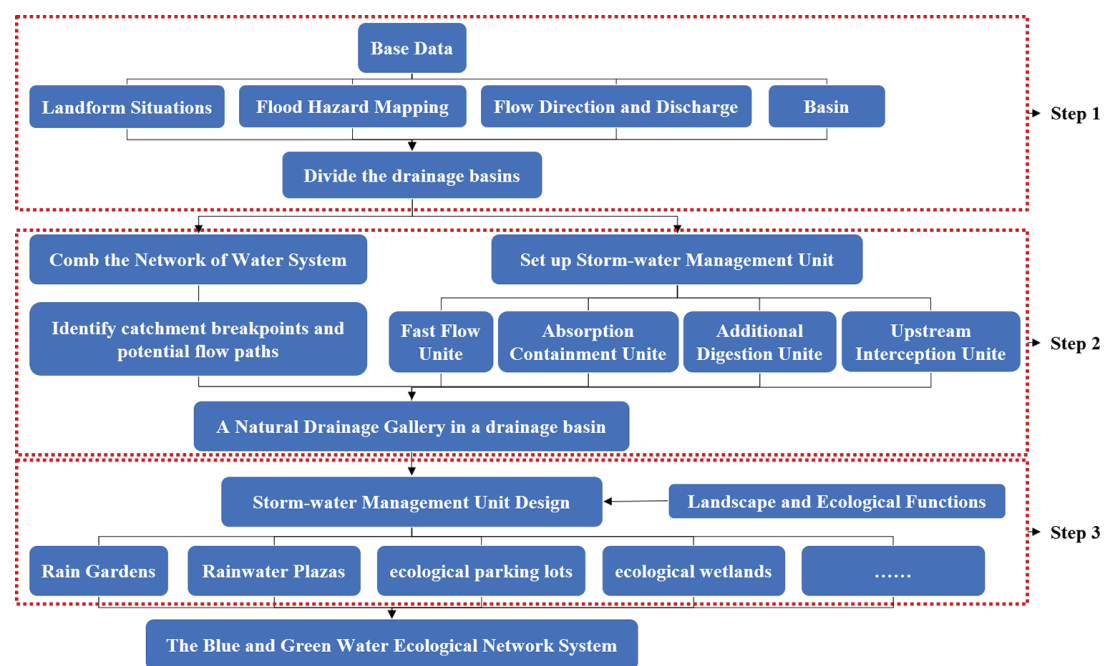

Figure 3: Blue-green ecological network construction flow chart.

\subsection{Landscape intervention}

Blue and green infrastructure often carries a natural scientific or technical interpretation which involves some limitations in perspective [17]. Research shows that focusing only on natural science and technological means creates unnecessary disputes among stakeholders [18]. The social and cultural value of blue-green networks should not be ignored. The intervention of landscaping means in the specific design process of rainwater management can effectively integrate the ecological value and humanistic value of a blue-green network. The blue-green ecological network construction process is shown in Fig. 3.

\section{RESULT}

\subsection{Analysis}

The effects of storm surges, tides, and rising sea levels on the entire peninsula are not evenly distributed in terms of space and intensity. Partial areas may also be threatened by several types of disasters [19]. The way to deal with floods should be more localized. Despite this, the peninsula is high in the middle and low on the edge, and it is obvious that the lower elevation coastal areas are more seriously affected.

On the GIS platform, the surface DEM data of the peninsula with an accuracy of 3.0M was used for the analysis of surface runoff extraction, flow direction analysis, and basin analysis. From the analysis results, it can be observed that several independent surface runoffs formed on the surface of the peninsula after rainfall, are flowing from the center to the coast (Fig. 4a and b). According to the characteristics of the catchment, 17 drainage basins were integrated from the preliminary basin zoning results obtained from the analysis (Fig. 4c). The surface coverage of each basin is very different [20]. Subsequent research is carried out according to the basin division. The natural drainage network of each basin not only undertakes the function of flood management but also is given the landscape and ecological functions and, finally, organically forms a blue-green ecological network of the entire peninsula. 


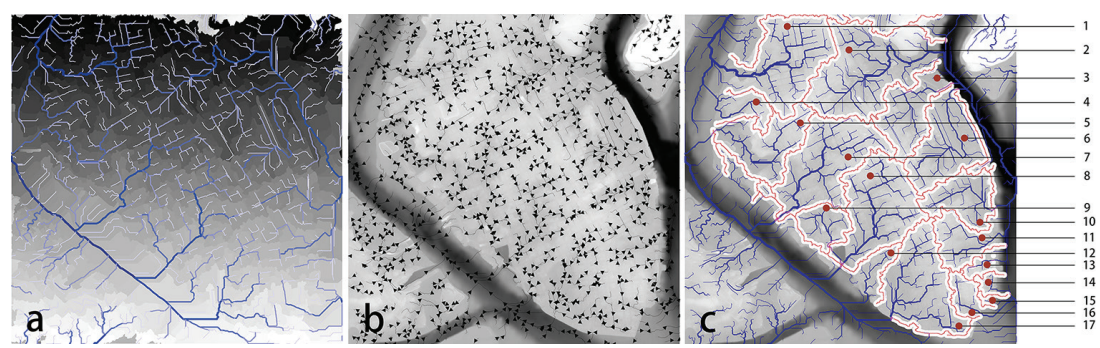

Figure 4: Hydrological analysis map of the peninsula. (a): Runoff extraction and classification; (b): Runoff direction analysis map; (c): Basin map of the peninsula.

\subsection{Planning}

The following section will explain the planning process from the construction of the blue network and the green network, so that the concept is better understood. The blue network includes guidance on the natural surface drainage process, and adopts specific measures, such as drainage, storage, and diversion for specific conditions. The green network means that the above water treatment is realized by landscape means to turn the threat into an opportunity. In order to better study the network, it is necessary to come down to a local scale of analysis. Taking Basin 8 as an example, the construction process of the blue-green ecological network of the basin and the micro-design of the stormwater management unit will be described in detail.

Basin 8 is located in the southwest of the peninsula. It is mainly composed of medium- and low-intensity development land but lacks large-scale green land. The largest body of water in Basin 8 is a triangular lake that is connected to the sea (Fig. 5a). After superimposing the runoff map with the 10-year flood basin map, it is found that the flooding area is mainly located at midstream and downstream of the runoff. It means the flood water volume has exceeded the load of both the pipeline drainage and natural drainage (Fig. 5b). However, there are still small flooding areas within Basin 8 where the main runoff does not flow. The presumed reason is that the local micro-topography makes the rainwater gather and cannot be smoothly discharged into the inlet, meanwhile rainwater cannot infiltrate, resulting in water accumulation.
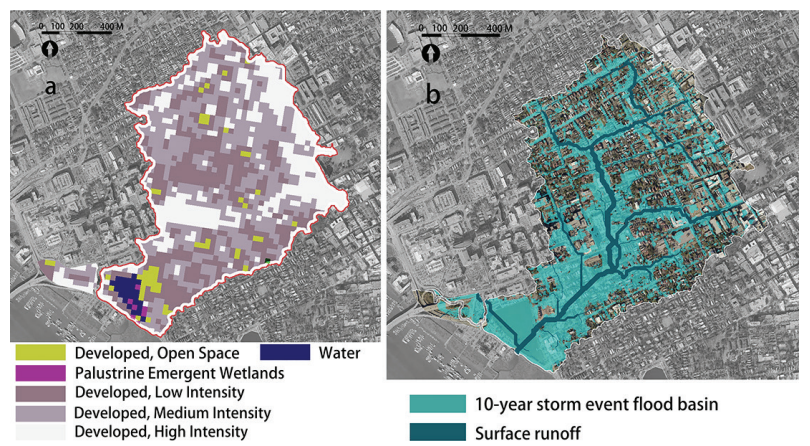

Figure 5: Basic information of Basin 8. (a): Land cover map of Basin 8. (Compilation by the authors from the sources [20].); (b): Runoff and the 10-year flood basin map of Basin 8. (Compilation by the authors from the sources [21].) 
The Stormwater Management Model (SWMM) is a dynamic precipitation-runoff simulation model used to simulate a single or long-term precipitation event or water quality simulation in a city. The model is now well developed and widely used. NOAA uses this model to evaluate the performance of existing rainwater harvesting systems in the Calhoun West service area of Charleston and simulate the combined effects of coastal flooding and precipitation to pinpoint when and where the stormwater system is at risk of being compromised (Calculation Example: Impacts of Coastal Flooding on Stormwater Infrastructure City of Charleston, South Carolina).

The study also divides the study area into several basins, each of which sets a node, and assumes that all surface runoffs within the basin eventually flow into the underground pipeline through the node. The analysis results are summarized as follows (the simulation results of Scenario 3 are not related to this study and are not mentioned). On the basis of the existing sea level in Scenario 1, if there is no tidal backflow valve in the pipeline network, seawater overflow will occur when the tide is high. Based on the rising sea level 25 years later (2043) for Scenario 2, most areas of the pipeline cannot meet drainage needs in the event of a tenyear storm. Scenario 3 assessed the most extreme situation. The condition at this time is that the sea level has risen after 25 years, and the peninsula faces both a 25 -year storm and a 2 -year rainfall runoff event. The distribution of pipeline flooding nodes is the same as that in Scenario 2, but the flooding duration is longer and the water depth is greater (Fig. 6).

Considering the actual working conditions of the drainage channel of Basin 8 and the surface flooding situation at the same time is conducive to a better analysis of the causes of water accumulation, so that flood management can be more specific. Therefore, the results of the above SWMM model analysis in Scenario 2 were geo-calibrated with Basin 8 . The area of the drainage overload in Basin 8 is then classified according to the degree of overload (Fig. 7a). There are many cases where the surface catchment watershed does not completely overlap with the underground pipeline service area (Fig. 7b). This does not affect the current analysis results.

Nodes such as J0.5, J1, J12, J41, and J42 predicted no overloading, but the 10-year flood map showed small floods in the service areas of these nodes. Therefore, the accumulation of water in these areas is likely due to poor water supply and the inability to smoothly discharge into underground pipelines. These areas are upstream of surface runoff, where the goal of flood management is to mitigate downstream drainage pressures without being flooded. The N10, N11, N12, and other nodes are overloaded with water for about 4 hours, but only some areas of the service area are flooded. One way to defer this situation is to divert the flood and

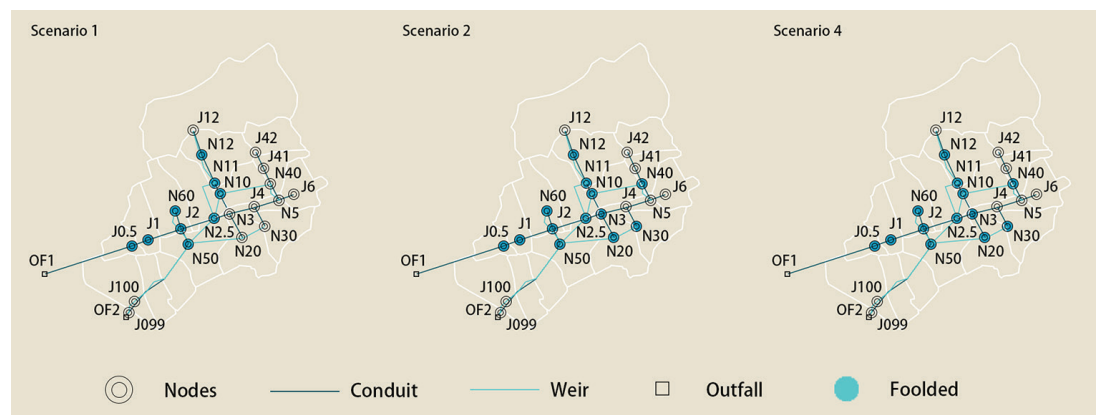

Figure 6: Flooding nodes in Scenario 1, Scenario 2, and Scenario 4. (Compilation by the authors from the sources [22].) 

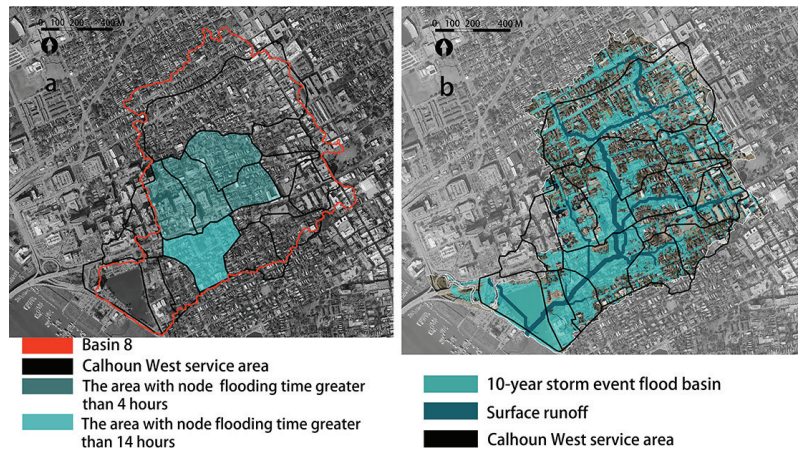

Figure 7: Comprehensive analysis map of hydrological processes. (a): The area of the drainage overload in Basin 8. (Compilation by the authors from the sources [22].); (b): Calhoun West service area geo-calibrated with runoff and 10-year event flood basin map. (Compilation by the authors from the sources [21]-[22].)

to avoid the peak hour. Node N50 is flooded for up to 14 hours, and its service area is located in a severe flooding zone just like the other downstream areas. However, these areas also have a certain scale of green spaces, wetlands, and water bodies. The main strategy for flood management of these areas should be to accelerate emissions while strengthening the temporary water storage function in partial areas. Combined with the flood management strategies for reducing the instantaneous flow of floods in other upstream areas, the flood damage intensity can be reduced and the flooding time shortened.

The first step in the planning section is to identify blocks with potential in Basin 8 based on two factors: surface runoff and 10 years of rainstorm flooding. These blocks are then classified according to residential areas, hard squares, roads, parking lots, green spaces, etc. (Fig. 8a). In particular, it is important to note that the level of potential depends on the condition of the underlying surface and the size of the area that can be modified. The second step is to divide the land into different stormwater management units based on the discussion of the three main governance strategies for different regions mentioned above. At the same time, the surface runoff is reorganized based on the original flow. The main guiding methods are microtopography reconstruction and the addition of low-impact means, such as culverts (Fig. 8b). There are four types of stormwater management units: fast flow zone, absorption containment zone, additional digestion zone, and upstream interception zone. Fast flow zone refers to the area where rainwater needs to be discharged as soon as possible. The absorption containment zone refers to the plot having a high potential for water treatment. After the landscape reconstruction, the rainwater seepage efficiency is improved, or a certain water storage function is realized. The goal of reducing runoff in this region will, therefore, be achieved. Additional digestion zone means the land is not located in the floodplain or where the major runoff passes, and it can provide flood diversion services for other heavily affected area. The upstream interception zone refers to an area located upstream of the runoff that does not flood. This zone can play a role in slowing downstream peaks by temporarily intercepting the water storage. When this part of the work is completed, most of the land in Basin 8 is defined as stormwater management units and connected through the surface and underground waterlines to form a blue system network within the area.

Within each stormwater management unit, corresponding landscape measures are proposed based on the current status of the land use, including rain gardens, rainwater plazas, 

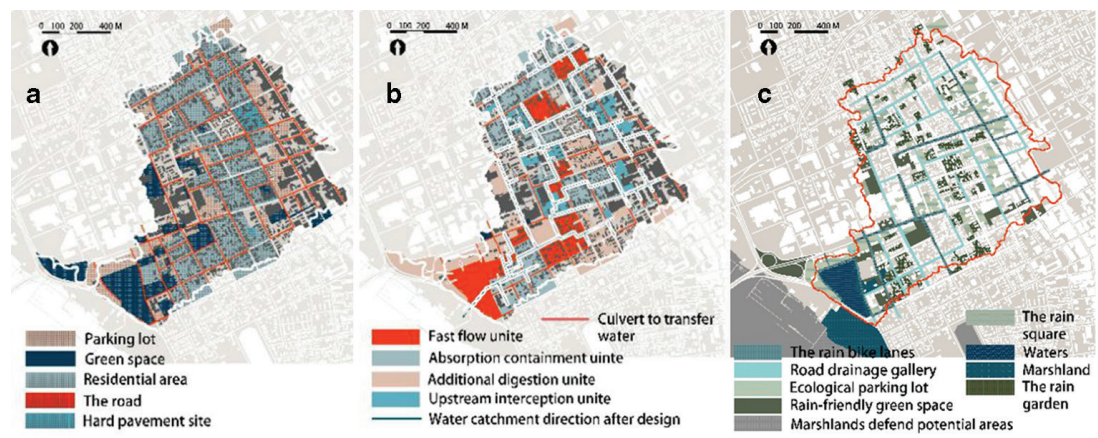

Figure 8: Map of the planning process. (a): Potential block classification map; (b): Stormwater management unit and reorganized surface runoff; (c): Landscape measures map of stormwater management.

ecological parking lots, rain-friendly green spaces, ecological wetlands, road drainage corridors, and rain bicycle lanes where the upper plan of the bicycle lane is used as the basis for road selection (Fig. 8c). Most of the land types in Basin 8 belong to residential areas that have a certain area of hard paved ground or green space. The rain garden is small and flexible and can be easily placed in the gaps between housing constructions within these areas. In addition, the total number of parking lots and hard paved plazas is large with sufficient space to build underground reservoirs and other water management facilities. Meanwhile, the parking lot was integrated into this opportunity to improve land use efficiency. Under the premise that the total number of parking spaces is not reduced, more land is replaced by community open space. Terrain adjustments, vegetation modifications, and other strategies are applied to natural green spaces, such as parks and wetlands, to improve rainwater regulation and purification. Water-compatible new public spaces, such as rainwater theme parks and floating sport fields, have also been proposed; the treated rainwater can be used as landscape water in these places. Roads are an important element in connecting the rainwater control unit. The control methods adopted for some roads with poor drainage include: replacement of permeable pavement, micro-slope matching grass drainage ditch, etc. The runoff on the road eventually enters the underground drainage system or the underground purification and storage device installed in the green space and parking lot. The planned bicycle lanes should combine function of use with rainwater management function. In this way, a green network has been built.

\subsection{Map details}

Near the southwest side of the site, two green spaces outside Basin 8 are presented on maps. The one on the north is the green space under the highway, and the other one is the wetland connected to the Ashley River. According to field research, the green space under the highway is in a state of ruin. It is located downstream of the surface runoff of Basin 9 and is close to the flood-hit area of Basin 8. Therefore, it has important regulation and storage impacts for both Basin 9 and Basin 8. According to the runoff analysis of the entire peninsula, the runoff of Basin 9 eventually enters the triangular lake of Basin 8 (Fig. 4c). It is recommended that the runoff of Basin 9 be diverted, so that it eventually passes through the green space under the highway to alleviate flooding in Basin 8. This space can also serve as a temporary storage block for Basin 8. 
Basin 8 is also threatened by storm surges. During these disasters, there are huge waves from the sea in addition to the heavy rainfall. According to records, the maximum wave height caused by a hurricane in Charleston between 2015 and 2017 was about 9 feet [5]. The infrastructure, houses, and even the lives of residents near the coast are threatened by huge waves. Therefore, the wetland between the Ashley River and the peninsula has an important buffering effect. Using organic means, such as capturing and accumulating silt and cultivating oyster reefs, is planned to promote the organic growth of narrow wetlands and form an effective wave buffer zone.

\section{DISCUSSION}

People's activity spaces can be divided into active-recreation spaces and passive-recreation spaces. Active-recreation space refers to the destinations, such as city parks, where the residents have clear travel needs and have time constraints. Passive-recreation space refers to the space in the process of the residents' work, daily life, commuting, and so on. Most of the southern end of the Charleston Peninsula is a historical block. The land type is relatively simple and lacks sufficient open space. Through this plan, the public space system of the peninsula can be established. Taking Basin 8 as an example, the reconstructed green spaces, wetlands, and other spaces can form a new type of high-quality active-recreation space. Spaces like community rain gardens, ecological parking lots, and rain bike lanes act as passive-recreation spaces, connecting scattered open spaces to form a complete network. Therefore, the blue-green ecological network proposed in this study is a functional composite spatial configuration for the Charleston Peninsula. It is also a strategic means to reconcile multifaceted issues such as disaster, ecology, and space utilization.

This research mainly involves the process of network construction and provides an idea for overall planning and regulation. The previous hydrological analysis stage has certain limitations in terms of data and analysis methods, and the performance problems after completion have not been considered. Blue and green infrastructure often carries a natural scientific or technical interpretation, which involves some limitations in perspective [23]. Collaborative planning is needed to integrate urban retrofitting, development processes, and flood risk management [24]. A robust framework requires a combination of four vulnerability reduction functions: threshold capacity, coping capacity, recovery capacity, and adaptive capacity [25]. This study takes the Charleston peninsula as an example to describe one of the physical space construction processes of the blue-green network system. In practical application, factors such as evacuation shelters, social capital, repair, and reconstruction should also be considered.

The extraction of runoff direction and the division of the watershed are based on the basic analysis method of hydrology. Urban hydrology is easily affected by land use and infrastructure, and it is still a complex task to determine drainage networks and watershed boundaries in highly urbanized river basins [26]. Increasing numbers of tools, such as Geo-PUMMA, are being developed to simulate urban or suburban hydrological processes. Similar research will also become more practical with the further optimization of analytical tools. It is reported that government agencies and academic institutions are very concerned about the floods in Charleston and are conducting more in-depth research. It is believed that future research results of the above departments can provide useful scientific support for the subsequent urban planning and design.

\section{ACKNOWLEDGEMENTS}

We should like to thank Professor Robert R. Hewitt and Hala F. Nassar (Clemson University) for their help in Collecting basic information and Field investigation. We also want to thank 
Professor Li Zhang and Wei Zhang (Huazhong Agricultural University), for their valuable comments. This research was funded by the Creative Research Program of DDON Planning\&Design Inc.

\section{REFERENCES}

[1] Shishegar, S., Duchesne, S. \& Pelletier, G., Optimization methods applied to stormwater management problems: A review. Urban Water Journal, 15(3), pp. 1-11, 2018. https:// doi.org/10.1080/1573062x.2018.1439976

[2] Sadeghi, K.M., Loáiciga, H.A. \& Kharaghani, S., Stormwater control measures for runoff and water quality management in urban landscapes. JAWRA Journal of the American Water Resources Association, 54(1), pp. 124-133, 2018. https://doi. org/10.1111/1752-1688.12547

[3] Rivers, E., McMillan, S., Bell, C. \& Clinton, S., Effects of urban stormwater control measures on denitrification in receiving streams. Water, 10(11), p. 1582, 2018. https:// doi.org/10.3390/w10111582

[4] Eaton, T.T., Approach and case-study of green infrastructure screening analysis for urban stormwater control. Journal of Environmental Management, 209, pp. 495-504, 2018. https://doi.org/10.1016/j.jenvman.2017.12.068

[5] Historic Events; Charleston, SC-Official, https://www.charleston-sc.gov/2007/Historic-Events

[6] Trees to Offset Stormwater, Case Study 04: Charleston, South Carolina; SC Forestry Commission, Green Infrastructure Center, the City of Charleston, Forest Service Department of Agriculture, https://www.charleston-sc.gov/DocumentCenter/View/19091/ Trees-and-Stormwater-Study-Charleston-SC-2018?bidId=, (accessed August 2018)

[7] Wagner, I., Krauze, K. \& Zalewski, M., Blue aspects of green infrastructure. Sustainable Development Applications, 4, pp. 145-155, 2013. https://doi.org/10.1016/j.jenvman.2017.12.068

[8] Hong, S.K., Nakagoshi, N. Fu, B.J. \& Morimoto (eds.), Y., Landscape ecological applications in man-influenced areas. Landscape Ecology, 23(10), pp. 1291-1292, 2008. https://doi.org/10.1007/s10980-008-9286-8

[9] Hugo, P., The network approach: Dutch spatial planning between substratum and infrastructure networks. European Planning Studies, 15(5), pp. 667-686, 2007. https:// doi.org/10.1080/09654310701213962

[10] Burns, M.J., Fletcher, T.D., Walsh, C.J., Ladson, A.R. \& Hatt, B.E., Hydrologic shortcomings of conventional urban stormwater management and opportunities for reform. Landscape and Urban Planning, 105(3), pp. 230-240, 2012. https://doi. org/10.1016/j.landurbplan.2011.12.012

[11] Lawson, E., Thorne, C., Ahilan, S., Allen, D., Arthur, S., Everett, G., ... \& Kilsby, C., Delivering and evaluating the multiple flood risk benefits in blue-green cities: An interdisciplinary approach. In Flood Recovery Innovation and Response IV, eds. D. Proverbs \& C.A. Brebbia, 184, pp. 113-124, 2014. https://doi.org/10.2495/friar140101

[12] De Sousa, T.M.I. \& Da Paz, A.R., How to evaluate the quality of coarse-resolution DEM-derived drainage networks. Hydrological Processes, 31(19), pp. 3379-3395, 2017. https://doi.org/10.1002/hyp.11262

[13] Bell, C.D., Mcmillan, S.K., Clinton, S.M. \& Jefferson, A.J., Hydrologic response to stormwater control measures in urban watersheds. Journal of Hydrology, 541, pp. 1488-1500, 2016. https://doi.org/10.1016/j.jhydrol.2016.08.049 
[14] Jankowfsky, S., Branger, F., Braud, I., Gironás, J. \& Rodriguez, F., Comparison of catchment and network delineation approaches in complex suburban environments: application to the Chaudanne catchment, France. Hydrological Processes, 27(25), pp. 3747-3761, 2013. https://doi.org/10.1002/hyp.9506

[15] Kong, F., Ban, Y., Yin, H., James, P. \& Dronova, I., Modeling stormwater management at the city district level in response to changes in land use and low impact development. Environmental Modelling \& Software, 95, pp. 132-142, 2017. https://doi.org/10.1016/ j.envsoft.2017.06.021

[16] Ahern, J., Urban landscape sustainability and resilience: The promise and challenges of integrating ecology with urban planning and design. Landscape Ecology, 28(6), pp. 1203-1212, 2012. https://doi.org/10.1007/s10980-012-9799-z

[17] Assmuth, T., Hellgren, D., Kopperoinen, L., Paloniemi, R. \& Peltonen, L., Fair blue urbanism: demands, obstacles, opportunities and knowledge needs for just recreation beside Helsinki Metropolitan area waters. Urban Sustain, 9(3), pp. 253-273, 2017. https://doi.org/10.1080/19463138.2017.1370423

[18] Kati, V. \& Jari, N., Bottom-up thinking-Identifying socio-cultural values of ecosystem services in local blue-green infrastructure planning in Helsinki, Finland. Land Use Policy, 50, pp. 537-547, 2016. https://doi.org/10.1016/j.landusepol.2015.09.031

[19] NOAA Coastal Flood Exposure Mapper; NOAA Office for Coastal Management, https://coast.noaa.gov/digitalcoast/tools/flood-exposure, (accessed 26 April 2019)

[20] Data Access Viewer; NOAA Office for Coastal Management, Online, https://coast. noaa.gov/dataviewer/\#/lidar/search/

[21] Calhoun West Drainage Improvement \& Sea Level Rise Mitigation Project, Watershed Assessment; City of Charleston, https://www.arcgis.com/apps/MapJournal/index.html ?appid=7cd50ff336e04e44820bec01f816a9d5

[22] Analyze Stormwater Systems, Calculation Example: Impacts of Coastal Flooding on Stormwater Infrastructure-City of Charleston, South Carolina; NOAA Office for Coastal Management, https://coast.noaa.gov/stormwater-floods/analyze/

[23] Assmuth, T., Hellgren, D., Kopperoinen, L., Paloniemi, R. \& Peltonen, L., Fair blue urbanism: Demands, obstacles, opportunities and knowledge needs for just recreation beside Helsinki Metropolitan area waters. Urban Sustain, 9(3), pp. 253-273, 2017. https://doi.org/10.1080/19463138.2017.1370423

[24] Van Herk, S., Zevenbergen, C., Ashley, R. \& Rijke, J., Learning and action Alliances for the integration of flood risk management into urban planning: A new framework from empirical evidence from the Netherlands. Environmental Science and Policy, 14(5), pp. 543-554, 2011. https://doi.org/10.1016/j.envsci.2011.04.006

[25] De Graaf, R.E., van de Ven, F.H.M. \& van de Giesen, N.C., The closed city as a strategy to reduce vulnerability of urban areas for climate change. Water Science and Technology, 56(4), pp. 165-173, 2007. https://doi.org/10.2166/wst.2007.548

[26] Kayembe, A. \& Mitchell, C.P.J., Determination of subcatchment and watershed boundaries in a complex and highly urbanized landscape. Hydrological Processes, 32(18), pp. 2845-2855, 2018. https://doi.org/10.1002/hyp.13229 